\title{
Factors Influencing Teenage Pregnancy in the Lower Manya Krobo Municipality in the Eastern Region of Ghana: A Cross-Sectional Study
}

\author{
John Yao Bedzo*, Stephen Manortey \\ Ensign College of Public Health, Kpong, Ghana \\ Email: *johnbedzo@st.ensign.edu.gh
}

How to cite this paper: Bedzo, J.Y. and Manortey, S. (2019) Factors Influencing Teenage Pregnancy in the Lower Manya Krobo Municipality in the Eastern Region of Ghana: A Cross-Sectional Study. Open Access Library Journal, 6: e5966.

https://doi.org/10.4236/oalib.1105966

Received: November 29, 2019

Accepted: December 24, 2019

Published: December 27, 2019

Copyright () 2019 by author(s) and Open Access Library Inc.

This work is licensed under the Creative Commons Attribution International License (CC BY 4.0).

http://creativecommons.org/licenses/by/4.0/

\begin{abstract}
Aim: This study attempted to 1) assess the factors contributing to teenage pregnancy in the Lower Manya Krobo Municipality; 2) specifically determine whether peer influence and sexual behaviour, electronic media and poverty, knowledge and use of contraceptives, and sex education contributed to teenage pregnancy; and 3) also determine the prevalence of teenage pregnancy and finally solicit for suggestions on how to curb the problem. The findings will help inform policymakers to further set in place measures to mitigate its adverse effects. Methods: A cross-sectional study was conducted to assess the prevalence of teenage pregnancy and its predictors among the target population between January and March 2019. Structured questionnaires were administered to 223 selected teenagers in a face-to-face interview setting within eight selected communities in the municipality by trained fieldworkers. Descriptive estimates including the prevalence of the condition were calculated. Both crude and adjusted logistic regression analyses were performed to examine the level of associations between selected variables. Conclusion: Teenage pregnancy is a public health threat in the municipality. There is, therefore, the need for the establishment of more "teenage health corners" to cater for the health needs of the teenagers. An extensive and devoted focus on girl-child education is also an important solution to deal with the increasing prevalence of teenage pregnancy.
\end{abstract}

\section{Subject Areas}

Education, Psychology, Sociology

\section{Keywords}

Teenager, Pregnancy, Sex, Lower Manya Krobo Municipality, Ghana 


\section{Introduction}

The increasing rate of teenage pregnancy in recent times has become a global concern across both developed and developing countries. This phenomenon is a social issue and of great public health importance which has received a lot of attention globally. It plaques both developed and developing countries, but it is more prevalent in developing countries, especially those in Sub-Saharan Africa. The 2014 World Health Statistics indicates that the average global birth rate among 13 to 19 -year-olds is 49 per 1000 girls. Country rates range from 1 to 299 births per 1000 girls with the highest rates in sub-Saharan Africa. There has been a marked down although an uneven decrease in the birth rates among teenage girls since 1990, but some $11 \%$ of all births worldwide are still to girls aged 13 to 19 years. The vast majority of these births (95\%) occur in low and middle-income countries where the experience of poverty, sexual abuse, and other social factors contribute to teenage pregnancies [1].

According to the WHO, "about 16 million teenage girls of the ages 15 and 19 years give birth each year". The babies born to these teenagers constitute approximately $11 \%$ of births worldwide. Out of this, $95 \%$ occur in developing countries or low-middle income countries [2]. However, in developed countries such as the Netherlands teenage birth rate is decreasing, and stands at 4.5 per 1000 births. Kost et al., (2014) indicated the United States of America (USA) has abstractly defined teenage pregnancy as "every under-age girl who becomes pregnant" [3]. The United Nations Children's Fund (UNICEF) defines teenage pregnancy as "a teenage girl, usually within the ages of 13 and 19 becoming pregnant" [4]. United Kingdom's (UK) definition of teenage pregnancy is more specific. The UK defines teenage pregnancy as a girl who before her eighteenth (18th) birthday becomes pregnant [5].

The United Nations defines youth to encompass all persons 15 - 24 years which appears to be a universal definition [6]. However, due to differences in national policies, this age range often turns to vary, leading to an overlap in the definition for teenagers, adolescents, and youth in general. For statistical purposes and for the framework of this study, teenage pregnancy is defined as getting pregnant at the teenage or adolescent period which spanned between 10 and 19 years.

The rate of pregnancy before marriage is reported being high in Latin America and the Caribbean and some parts of Sub-Saharan Africa (SSA) as compared to that of Asia [7]. The UNFPA in "The State of World Population Report 2013" stated that West and Central Africa account for the highest percentage (6\%) of reported births before age 15 years among developing countries. There has been variation in the birth rate of teenage girls between the ages of 15 and 19 years in Sub-Saharan Africa in recent years. The variation ranges from 37 births per 1000 girls in Mauritius to 229 births per 1000 girls in Guinea. The country of Niger tops the list at 203.604 births per 100,000 teenage women. Going on down the line following Niger are Mali (175.4438), Angola (166.6028), Mozambique (142.5334), Guinea (141.6722), Chad (137.173), Malawi (136.972), and Coted' 
Ivoire (135.464) [8]. Teenage births in low and middle-income countries are twice higher compared to that of more developed countries [8].

In Ghana, 9.2\% of adolescents between ages 15 and 19 years were reported married and 3.2\% were living with their partners though not married [9]. Also, $5.2 \%$ of teenagers between the ages of 12 and 14 years were married according to the Ghana Statistical Service report (2010). In the Brong Ahafo Region of Ghana, $7.8 \%$ of females teens between ages 15 and 19 were found to be married with $3.8 \%$ between the ages of 12 and 14 years [9]. Teenage pregnancy is also high in most high income or developed countries such as the United States of America. Teenage pregnancy has become common in most Ghanaian societies. It is seen mostly in teenagers in the Basic, Junior High, and Senior High schools. One (1) out of eight (8) pregnancies in Ghana happens to be a teenager [10]. Statistics from the Brong-Ahafo Regional Girl Child Education Network have revealed that in the 2016/2017 academic year, the region recorded 778 pregnancies, 144 in the Primary School, 573 in Junior High and 91 in Senior High Schools. There was a record of 572 teenage pregnancy in the Shama District of the Western Region and a reported mass failure of female candidates who sat for the BECE (Basic Education Certificate Examination) in that area [11]. In the Manya Krobo Municipality in the Eastern Region of Ghana, more than thirty-three (33) female students were not able to sit for their BECE due to pregnancy [12]. In the Sunyani West District of the Brong Ahafo Region, 259 teenage pregnancies were recorded from January to June 2014 [13].

Description of the teenage pregnancy rates would usefully guide national policy and decision making on factors influencing teenage pregnancy and how its impact could be mitigated. The main aim of this study was to determine the prevalence and factors associated with teenage pregnancy among teenagers in the municipality.

\section{Research Design}

The study was conducted in the Lower Manya Krobo Municipality (LMKM).The study was conducted in the Lower Manya Krobo Municipality. The Municipal is one of the twenty-six (26) Municipalities and Districts in the Eastern Region of Ghana. It lies between latitude $6.05^{\circ} \mathrm{S}$ and $6.30^{\circ} \mathrm{N}$ and longitude $0.08^{\circ} \mathrm{E}$ and $0.20^{\circ} \mathrm{W}$. The administrative capital of the Municipality is Odumase-Krobo. The Municipality covers a land area of about $1476 \mathrm{~km}^{2}$, constituting about $8.1 \%$ of the total land area within the region $\left(18,310 \mathrm{~km}^{2}\right)$. The Lower Manya Krobo Municipal is divided into six sub-Municipalities for the purposes of planning and delivery of health services [8].

A descriptive cross-sectional study was conducted between January and March 2019 among teenagers to assess the prevalence of teenage pregnancy and its predictors. The sample size was calculated using the Cochran's formula for estimation of a single proportion,

$$
n=\frac{z^{2} \times(p q)}{e^{2}}
$$


where,

$z=$ value is taken as 1.96

$p=$ the prevalence of teenage pregnancy from literature review (15.7\%) [14];

$q=$ the proportion of teenager not involved in teenage pregnancies;

$e=$ the margin of error of estimation, was assumed to be $5 \%$ or 0.05 ;

$n=$ is the estimated sample size.

This provided a sample size of 203. And with a $10 \%$ non-response rate, the final sample size was derived to be 223 students. The study participants were then selected using convenience sampling techniques.

\subsection{Data Management}

A self-administered structured questionnaire consisting of both opened and closedended questions were developed based on findings from reviewed literature. The anonymous questionnaire covers socio-demographic factors in addition to other influential factors of teenage pregnancy. The questionnaire was administered by field assistants who were trained on the nature of the study, confidentiality, voluntary participation and how to collect the quantitative data. Pre-testing of the questionnaire was undertaken among 15 percent of the sample size (34 teenagers outside the municipality but close to the study area) in similar areas before the actual data collection took place and corrections were made thereafter to improve the clarity of some items. Information on the study subjects regarding their demographic characteristics, electronic/social media, peer influence, sexual behavior, sex education, knowledge and use of contraceptive, family-related factors, and other factors were obtained through in-person interviews.

The dependent variable was "pregnancy status" and used as such in the logistic regression analysis in this study. The explanatory variables explored included socio-demographic factors (age, gender, marital status, religion, education, etc.), electronic/social media, peer influence, sexual behavior, sex education, knowledge and use of contraceptive and family-related factors.

\subsection{Statistical Analysis}

Data analysis is the process of systematically applying statistical and/or logical techniques to describe, illustrate, condense, recap, and evaluate data [15] [16] describes data analysis as the ordering and breaking down of data into constituent parts and performing of statistical calculations with the raw data to provide answers to the research questions which initiate the research. The unit of analysis refers to the specific object to be studied that can be an individual, group, book, town and the like [17].

The data were coded, entered, cleaned, and analyzed using Microsoft Excel version 2016 and STATA statistical software package (StataCorp. 2007. Stata Statistical Software. Release 14. StataCorp LP, College Station, TX, USA). Univariate analysis of selected variables was conducted to generate descriptive statistics on the socio-demographic characteristics of the participants. Bivariate and 
multivariate analyses were carried out using the Fisher's Exact Chi-square test to assess the level of association among selected variables and logistic regression to examine the relationship between the outcome variable of pregnancy status and selected predictors. Adjusted and unadjusted odds ratios (OR) and their 95\% confidence intervals $(\mathrm{CI})$ were used as indicators to measure the strength of association. A p-value of 0.05 or less was used as the cut-off level for statistical significance (Table 1).

\subsection{Ethics Statement}

Ethical clearance was obtained from the Institutional Research Ethics Review Board of Ensign College of Public Health. Administrative approvals were also sought from the various governmental and traditional leaderships that have jurisdiction over the participatory communities. The objective of the study was explained to all study participants. They were briefed about the confidentiality of their response and the importance of providing correct and accurate information, and that participation was voluntary. All participants included in the study have provided written consent. Finally, all documents such as professional and academic articles and other published papers that were collected were duly acknowledged in the reference list.

\section{Study Population Characteristics}

A total of 223 subjects participated in the study which generated a response rate of $100 \%$. The ages of the subjects ranged from 10 to 19 years with a mean age of $16.6 \pm 2.32$ years. While $2(0.90 \%)$ of the respondents were married, 8 (3.59\%) were co-habiting and the majority $213(95.52 \%)$ reported being single at the time of the study. The majority, 153 (68.61\%) of the study participants indicated being enrolled in schools whilst the remaining 70 (31.39\%) were not at the time of the study. Many of the subjects reported some level of formal education with only 11 (4.93\%) mentioned not having any form of formal education. Almost ninety-four percent of the respondents professed faith in Christianity whilst the rest belonged to other religious faiths. The majority of the respondents were of the Krobo and Ewes ethnic backgrounds. Regarding what the study subjects do for a living, the majority of them stated being students/pupils 150 (67.26\%) whilst the rest were either artisans, drivers, civil servants unemployed. Almost $44 \%$ of the study participants mentioned they had ever experienced pregnancy

Table 1. List of variables.

\begin{tabular}{cc}
\hline Dependent Variable & Independent Variables \\
\hline Pregnancy Status & Peer influence and sexual behaviour \\
Electronic/Social Media \\
Family-related factors \\
Level of Education and Sex Education \\
Knowledge and use of Contraceptives (Family planning) \\
\hline
\end{tabular}


whilst the rest have not (Table 2).

Table 2. Socio-demographic characteristics of the study population.

\begin{tabular}{|c|c|}
\hline Variable $(\mathrm{N}=223)$ & N (\%) \\
\hline \multicolumn{2}{|l|}{ Age Group } \\
\hline $10-13$ yrs & $40(17.94)$ \\
\hline $14-17 \mathrm{yrs}$ & $97(43.5)$ \\
\hline $18-19$ yrs & $86(38.57)$ \\
\hline \multicolumn{2}{|l|}{ Marital Status } \\
\hline Single & $213(95.52)$ \\
\hline Co-habiting & $8(3.59)$ \\
\hline Married & $2(0.9)$ \\
\hline \multicolumn{2}{|l|}{ Currently in School } \\
\hline Yes & $153(68.81)$ \\
\hline No & $70(31.39)$ \\
\hline \multicolumn{2}{|l|}{ Highest Education Level } \\
\hline None & $11(4.93)$ \\
\hline Primary & $52(23.32)$ \\
\hline JHS & $98(43.95)$ \\
\hline SHS & $62(27.80)$ \\
\hline \multicolumn{2}{|l|}{ Religious Affiliation } \\
\hline Christianity & $208(93.27)$ \\
\hline Islam & $10(4.48)$ \\
\hline Traditional & $5(2.24)$ \\
\hline \multicolumn{2}{|l|}{ Ethnic Background } \\
\hline Krobo & $162(72.65)$ \\
\hline Ewe & $35(15.70)$ \\
\hline Akan & $24(10.76)$ \\
\hline $\mathrm{Ga}$ & $2(0.90)$ \\
\hline \multicolumn{2}{|l|}{ Place of Birth } \\
\hline Within the LMKM & $167(74.89)$ \\
\hline Outside the LMKM & $56(25.11)$ \\
\hline \multicolumn{2}{|l|}{ Number of Children } \\
\hline 0 & $187(83.86)$ \\
\hline 1 & $35(15.70)$ \\
\hline 2 & $1(0.45)$ \\
\hline \multicolumn{2}{|l|}{ Pregnancy Status } \\
\hline Yes & $98(43.95)$ \\
\hline No & $125(56.05)$ \\
\hline \multicolumn{2}{|l|}{ Occupation } \\
\hline None & $25(11.21)$ \\
\hline Trading & $28(12.56)$ \\
\hline Students/pupils & $150(67.26)$ \\
\hline Artisan & $17(7.62)$ \\
\hline Teaching & $3(1.35)$ \\
\hline
\end{tabular}

Note: LMKM stands for Lower Manya Krobo Municipality. 
A bivariate analysis (Table 3 ) to test the level of association of selected socio-demographic factors and pregnancy status of the subjects clearly revealed significant statistical associations between the response variable (pregnancy status) and the independent variables such as age, marital status, current enrollment status and occupation of the subjects $(\mathrm{p}<0.0001)$. However, the reported highest level of education attained by the study participants showed no statistically significant association with the outcome variable.

\subsection{Other Influential Factors of Teenage Pregnancy}

The results from the study showed that almost all the respondents 208 (93.28\%) either own or share mobile phones with family members. About their choice of social media activities, $68(30.49 \%)$ of the subjects were into WhatsApp, 45 (20.18\%) into Facebook, 7 (3.14\%) into YouTube, 4 (1.80\%) into Twitter and 99 (44.39\%) reported not engaging in any of the listed social activities. On the question regarding ever engaged in sexual intercourse, $109(48.88 \%)$ of them acknowledged an exposer whilst the remaining $114(51.12 \%)$ of them reported

Table 3. Bivariate analysis of demographic characteristics on pregnancy status.

\begin{tabular}{|c|c|c|c|}
\hline Variable $\mathrm{N}=223$ & $\begin{array}{c}\text { Pregnant } \\
\mathrm{n}=98(\%)\end{array}$ & $\begin{array}{c}\text { Non-Pregnant } \\
n=125(\%)\end{array}$ & P-Value \\
\hline \multicolumn{4}{|l|}{ Age Group } \\
\hline $10-13$ yrs & $1(1.02)$ & $39(31.20)$ & $<0.001^{*}$ \\
\hline $14-17$ yrs & $25(25.51)$ & $72(57.60)$ & \\
\hline $18-19$ yrs & $72(73.47)$ & $14(11.20)$ & \\
\hline \multicolumn{4}{|l|}{ Marital Status } \\
\hline Single & $88(89.80)$ & $125(100)$ & $<0.001^{\star}$ \\
\hline Co-habiting & $8(8.16)$ & $0(0.00)$ & \\
\hline Married & $2(2.04)$ & $0(0.00)$ & \\
\hline \multicolumn{4}{|l|}{ Currently in School } \\
\hline Yes & $33(33.67)$ & $120(96.00)$ & $<0.001^{*}$ \\
\hline No & $65(66.33)$ & $5(4.00)$ & \\
\hline \multicolumn{4}{|l|}{ Highest Education Level } \\
\hline None & $7(7.14)$ & $4(3.20)$ & 0.086 \\
\hline Primary & $24(23.47)$ & $29(23.20)$ & \\
\hline JHS & $35(35.71)$ & $63(50.40)$ & \\
\hline SHS & $33(33.67)$ & $29(23.20)$ & \\
\hline \multicolumn{4}{|l|}{ Occupation } \\
\hline None & $22(22.45)$ & $3(2.40)$ & $<0.001^{*}$ \\
\hline Trading & $26(26.53)$ & $2(1.60)$ & \\
\hline Students/pupils & $32(32.65)$ & $118(94.40)$ & \\
\hline Artisan & $16(16.33)$ & $1(0.80)$ & \\
\hline Teaching & $2(2.04)$ & $1(0.80)$ & \\
\hline
\end{tabular}

Note: ${ }^{*}$ indicates the measured association is statistically significant at $\alpha<0.05$. 
exposed between the ages of 13 to 15 years while $6(5.50 \%)$ mentioned their involvement occurred between the ages of 10 to 12 years. Investigating further to tease out who initiated them the first time, about 60 (55.04\%) of them indicated either friends or by themselves, 44 (40.37\%) mentioned boy/girl lovers and 5 (4.59\%) indicated adult relatives. Again, of the 109 respondents who reported ever having sexual intercourse, $73(66.97 \%)$ did it consensually, whereas 32 $(29.36 \%)$ for financial gain and 4 (3.37\%) reported being raped. Out of the 109 subjects who had sex, 85 (77.98\%) had knowledge of contraceptives whilst 24 (22.02\%) did not. Again more than half reported never used any contraceptives whilst 51 (46.79\%) admitted using it (Table 4).

The study further measured the level of statistical association between selected influential variables and the pregnancy status among the respondents (Table 5). The following independent variables: ever had sex, peer influences on the desire to have sex, electric media influence on early sex, use of internet for social activities, religious activities include sex education, social media activity influence on sexual behavior and both parents living together were found to be significantly associated with the response variable (pregnancy status). The study again, however, revealed a lack of significant association between two (2) other variables and the respondents' reported pregnancy status at the time of the study. The household social economic status $(\mathrm{p}=0.741)$ and source of information on SRH $(\mathrm{p}=0.167)$.

\subsection{Determinants of Teenage Pregnancy, Multivariate Result}

In a multivariate Logistic regression analysis to assess the effect of each variable on the dependent variable (pregnancy status), it was observed that the respondents' age, the living situation of parents (whether living together), social media activity, influence on sexual behavior, enrollment status at school, and peer influence opinion on sex, did show strong association with pregnancy status among the study subjects. Though the bivariate analysis showed a significant difference in the pregnancy status by religious activities included in sex education, this difference disappeared in the multivariate logistic analysis (Table 6).

\section{Discussions}

A total of 223 teenagers participated in the study. The mean age of the study population was 16.16 (SD 2.32) years. A total of 98 (43.95\%) of the teenagers reported either pregnant or ever had live childbirth on or before their 19th birthday. Being in school, age, peer influence, occupation, parents living together, often use of the internet for social media, marital status and the use of electric media were identified to be statistically associated with pregnancy status $(\mathrm{p}<0.05)$. A multivariate logistic regression analysis indicated that older age (age group 18 19) (OR 51.00; 95\% CI 1.11 - 2254), teenagers being influenced by social media activities (OR 5.80; 95\% CI 1.65 - 20.24.34) and teenagers being influence by their peers (OR 8.00; 95\% CI 1.54 - 41.70) increased the odds of getting pregnant 
Table 4. Univariate analysis of some influential factors and teenage pregnancy status.

\begin{tabular}{|c|c|}
\hline Variable $(\mathrm{N}=223)$ & $\mathrm{N}(\%)$ \\
\hline \multicolumn{2}{|l|}{ How Mobile Phone Is Used } \\
\hline Own a mobile phone & $103(46.19)$ \\
\hline Share phone with families & $105(47.09)$ \\
\hline Share phone with friends & $8(3.58)$ \\
\hline Share SIM with friends & $7(3.14)$ \\
\hline \multicolumn{2}{|l|}{ Types of Social Activities } \\
\hline WhatsApp & $68(30.49)$ \\
\hline Facebook & $45(20.18)$ \\
\hline YouTube & $7(3.14)$ \\
\hline Twitter & $4(1.80)$ \\
\hline None & 99 (44.39) \\
\hline \multicolumn{2}{|l|}{ Had Sex } \\
\hline Yes & $109(48.88)$ \\
\hline No & $114(51.12)$ \\
\hline \multicolumn{2}{|c|}{ Among Only Those Ever Had Sex $(n=109)$} \\
\hline \multicolumn{2}{|l|}{ Age at First Sex, Years } \\
\hline $10-12$ & $6(5.50)$ \\
\hline $13-15$ & $58(53.21)$ \\
\hline $16-18$ & $45(41.28)$ \\
\hline \multicolumn{2}{|l|}{ Who Initiated You into First Sex? } \\
\hline Friend & $30(27.52)$ \\
\hline Myself & $30(27.52)$ \\
\hline Boy/girl lover & $44(40.37)$ \\
\hline Relative & $5(4.59)$ \\
\hline \multicolumn{2}{|l|}{ Reasons for the Initiation of Sex } \\
\hline Consensual Sex & $73(66.97)$ \\
\hline Rape & $4(3.37)$ \\
\hline Financial gains & $32(29.36)$ \\
\hline \multicolumn{2}{|l|}{ Knowledge of Contraceptive } \\
\hline Yes & $85(77.98)$ \\
\hline No & $24(22.02)$ \\
\hline \multicolumn{2}{|l|}{ Use of Contraceptive } \\
\hline Used & $51(46.79)$ \\
\hline Never Used & $58(53.21)$ \\
\hline
\end{tabular}

among the teenagers.

The findings from the study revealed a teenage pregnancy prevalence of 43.95\% among selected participants in the Lower Manya Krobo Municipality in the Eastern Region of Ghana. It further brought to light that demographic characteristics such as the respondents' age, marital status, and occupation, were 
Table 5. Bivariate analysis of some influential factors of pregnancy status.

\begin{tabular}{|c|c|c|c|}
\hline Variable $(\mathrm{N}=223)$ & $\begin{array}{c}\text { Pregnant } \\
\mathrm{n}=98(\%)\end{array}$ & $\begin{array}{c}\text { No Pregnant } \\
\mathrm{n}=125(\%)\end{array}$ & $\begin{array}{c}\text { Chi-square } \\
\text { P-value }\end{array}$ \\
\hline \multicolumn{4}{|l|}{ Had Sex } \\
\hline Yes & $98(100.0)$ & $11(8.80)$ & $<0.0001^{*}$ \\
\hline No & $0(0.0)$ & $114(91.20)$ & \\
\hline \multicolumn{4}{|l|}{ Peer Influences Opinion on Sex } \\
\hline Yes & $92(93.88)$ & $61(48.80)$ & $<0.0001^{*}$ \\
\hline No & $6(6.12)$ & $64(51.20)$ & \\
\hline \multicolumn{4}{|c|}{ Electric Media Influence Early Sex } \\
\hline Yes & $85(86.73)$ & $65(52.00)$ & $<0.0001^{*}$ \\
\hline No & $13(13.27)$ & $60(48.00)$ & \\
\hline \multicolumn{4}{|c|}{ Often Use of the Internet for Social Activities } \\
\hline Less than 4 times per day & $60(61.22)$ & $43(34.40)$ & $<0.0001^{*}$ \\
\hline 4 times and more per day & $11(11.22)$ & $9(7.20)$ & \\
\hline None & $27(27.55)$ & $73(58.40)$ & \\
\hline \multicolumn{4}{|c|}{ Do Religious Activities Include Sex Education? } \\
\hline Yes & $89(90.82)$ & $74(59.20)$ & $<0.0001^{*}$ \\
\hline No & $9(9.18)$ & $51(40.80)$ & \\
\hline \multicolumn{4}{|c|}{ Household Socio-Economic Status } \\
\hline Low & $17(17.35)$ & $26(20.80)$ & 0.741 \\
\hline Middle & $23(23.47)$ & $31(24.80)$ & \\
\hline High & $58(59.18)$ & $68(54.40)$ & \\
\hline \multicolumn{4}{|l|}{ Source of Information on SRH } \\
\hline Peer & $32(32.65)$ & $58(46.40)$ & 0.167 \\
\hline Parents/Guardians & $32(32.65)$ & $31(24.80)$ & \\
\hline Media/TV & $5(5.10)$ & $8(6.40)$ & \\
\hline Health Professionals/Teachers & $29(29.59)$ & $28(22.50)$ & \\
\hline \multicolumn{4}{|c|}{ Social Media Activity Influence on Sexual Behaviour } \\
\hline Yes & $55(56.12)$ & $15(12.00)$ & $<0.0001^{*}$ \\
\hline No & $43(43.88)$ & $110(88.00)$ & \\
\hline \multicolumn{4}{|l|}{ Do Parents Live Together? } \\
\hline Yes & $35(35.71)$ & $77(61.60)$ & $<0.0001^{*}$ \\
\hline No & $63(64.29)$ & $48(38.40)$ & \\
\hline
\end{tabular}

Note: ${ }^{\star}$ indicates the measured association is statistically significant at $\alpha<0.05$; ${ }^{\star}$ Household Socio-Economic status was derived through a Principal Component; Analysis of basic household assets.

significantly associated with the reported pregnancy status. The finding with regard to the age was consistent with the findings of the 2014 Ghana Demographic Health Survey (GDHS) Report [18].

It was further observed that individuals who were in the age group $18-19$ years at the time of the study were 51 times more likely to be pregnant compared 
Table 6. Logistic regression of influential factors and pregnancy status in the Lower Manya Krobo Municipality.

\begin{tabular}{|c|c|c|c|c|}
\hline Variable & P-Value & $\begin{array}{l}\text { Unadjusted } \\
\text { OR (95\% CI) }\end{array}$ & P-Value & $\begin{array}{c}\text { Adjusted } \\
\text { OR (95\% CI) }\end{array}$ \\
\hline \multicolumn{5}{|c|}{ Age, Years } \\
\hline $10-13$ & Reference & 1 & & 1 \\
\hline $14-17$ & $0.012^{*}$ & $13.50(1.77-103.77)$ & 0.353 & $6.00(0.14-262.42)$ \\
\hline $18-19$ & $<0.0001^{\star}$ & $200.60(25.41-1583)$ & $0.044^{\star}$ & $51.00(1.11-2254)$ \\
\hline \multicolumn{5}{|c|}{ Parents Live Together } \\
\hline No & Reference & 1 & & 1 \\
\hline Yes & $<0.001^{*}$ & $0.35(0.20-0.60)$ & $0.027^{\star}$ & $0.27(0.08-0.86)$ \\
\hline \multicolumn{5}{|c|}{$\begin{array}{c}\text { Social Media Activity } \\
\text { Influence on Sexual } \\
\text { Behavior }\end{array}$} \\
\hline No & Reference & 1 & & 1 \\
\hline Yes & $<0.001^{*}$ & $9.38(4.80-18.35)$ & $0.006^{*}$ & $5.80(1.65-20.24)$ \\
\hline \multicolumn{5}{|c|}{ Currently in School } \\
\hline No & Reference & 1 & & 1 \\
\hline Yes & $<0.001^{\star}$ & $0.02(0.008-0.06)$ & $<0.001^{*}$ & $0.02(0.01-0.08)$ \\
\hline \multicolumn{2}{|c|}{ Opinion on Sex } & & & \\
\hline No & Reference & 1 & & 1 \\
\hline Yes & $<0.001^{*}$ & $16.10(6.56-39.46)$ & $0.014^{\star}$ & $8.00(1.54-41.70)$ \\
\hline \multicolumn{5}{|c|}{$\begin{array}{l}\text { Do Religious Activities } \\
\text { Include Sex Education? }\end{array}$} \\
\hline No & Reference & 1 & & 1 \\
\hline Yes & $<0.001^{*}$ & $6.82(3.15-14.76)$ & 0.236 & $2.40(0.56-10.24)$ \\
\hline \multicolumn{5}{|c|}{$\begin{array}{l}\text { Household Social } \\
\text { Economic Status }\end{array}$} \\
\hline Low & Reference & 1 & & 1 \\
\hline Middle & 0.46 & $1.30(0.65-2.64)$ & 0.334 & $2.04(0.48-8.61)$ \\
\hline High & 0.761 & $1.13(0.50-2.56)$ & 0.199 & $2.94(0.57-15.22)$ \\
\hline
\end{tabular}

Note: ${ }^{*}$ indicates the measured association is statistically significant at $\alpha<0.05$.

to individuals aged 10 - 13 years holding all other variables constant. This finding, however, was consistent with the findings of the 2014 GDHS report which indicated that teenage pregnancy increased with age and teenagers are more likely to begin childbearing at an early age [18]. The study again found that there was a significant difference among the subjects with regard to pregnancy status with the majority of the subjects being single.

This finding is similar to what was reported in the 2008 GDHS Report, where teenage pregnancy was found to be among teenagers who had never been married [19]. The study established that a significant proportion of the respondents who reported getting pregnant $22(22.45 \%)$ were not working nor studying in school to acquire any skill. It is important to note that about $86.73 \%$ of impregnated teenagers and $52.0 \%$ of non-pregnant teenagers used electric media for at 
least one social media activity such as WhatsApp and Facebook. This corroborates a study by Selkie et al. (2011) which indicated that about $73 \%$ of teenagers use one form of social networking sites such as Facebook and WhatsApp [20].

In this study, the use of electriclsocial media, its activities and its influence on sexual behavior were found to influence teenage pregnancy. This finding is consistent with the findings of Strasburger et al. (2009) and Chandra et al. (2008) which presented the influence of the social media on early sexual behavior of teenagers and its consequences such as Sexually Transmitted Infection (STI) and unwanted pregnancy since most of the adolescents just look at the thrilling aspect of sex as depicted by the media and not its consequences [21] [22]. The study again established that the majority of teenagers use the internet once a day to listen to sexually explicit music and chat with people they don't know on their mobile phones. Connell (2009) states that preliminary evidence suggests that displays of sexual material on Facebook are associated with the reported intention to become sexually active among teenagers [23]. This agrees with the finding.

In this study, school enrollment status (whether currently in school or not) at the time of the study was also found to be a significant influential factor on the pregnancy status of the respondents $(\mathrm{OR}=0.02,95 \% \mathrm{CI}=0.008-0.06)$. Enrollment in school tends to serve as a protective factor for getting pregnant in both the unadjusted and adjusted predictive models. The respondents who reported being in school at the time of the study were 0.02 times less likely to become pregnant as compared to teenagers not currently in school. The issue of parents living together or not was also found to have a significant statistical influence on pregnancy status among teenagers $(\mathrm{OR}=0.27,95 \% \mathrm{CI}=0.08-0.86)$. Participants whose parents live together were 0.73 times less likely to become pregnant as compared to teenagers whose parents do not live together. This, therefore, confirmed the assertion by Odu (2007) that parents who leave their families put their daughters at a greater risk of early sexual activities which may result in teenage pregnancy [12].

The findings revealed that was no significant association between the economic status of parents/guardians and teenage pregnancy when the odds ratio was unadjusted. The findings from the study with respect to economic factors contradicted a study by Gyan (2013) that revealed that poverty has a great influence on adolescent pregnancy [24].

Peer influences opinion on sex $(\mathrm{OR}=16.1,95 \% \mathrm{CI}=6.56-39.46)$ and whether various churches include sex education in their activities $(\mathrm{OR}=6.82,95 \% \mathrm{CI}=$ 3.15 - 14.76) were all found to be a potential factor among the participants of the study. Teenagers who indicated that peers influence their opinion on sex were 8 times more likely to be pregnant compared to their counterparts whose opinions on sex are not influenced by their peers. This finding is consistent with that of the study by Amuyunzu-Nyamango et al. (2005) where most teenagers were reported to indulge in unsafe sexual behavior as a result of pressure from peers [25]. Smetena et al. (2006) have also linked teenage pregnancy to teenagers' sex- 
ual activities facilitated by peer pressure or influence [26].

Our findings indicate that household socio-economic status and sex education at a religious level were not statistically significant; it was observed that as household socioeconomic status changes from "Middle" to "High" status, the chances of the teenagers becoming pregnant increases from 2.04 to 2.94 when other covariates were adjusted for in the model. The finding contradicts a study by Gyan (2013) that revealed that poverty has a great influence on adolescent pregnancy [24]. It was clear that teenagers who indicated receiving sex education during their religious activities rather have 2.4 times higher chance of becoming pregnant as compared to those never received sex education at the same level. However, in the multivariate analysis, only household social economic status was found to be statistically insignificantly. This finding is contrary to the study by Adu-Gyamfi (2014) related to the lack of sex education to teenage pregnancy [27].

The findings of this study indicated that $76.29 \%$ of pregnant teenagers and $55.22 \%$ of the non-pregnant teenagers had knowledge of contraceptives. In total, $73.54 \%$ of the respondents of the study who heard of family planning had knowledge of at least one method of contraceptive. This is in line with the study by Awusabo-Asare et al. (2006) which stated that about $90 \%$ of teenagers between the ages of 12 and 19 years have knowledge of at least one modern method of contraceptive [28].

Notwithstanding the high rate of contraceptive knowledge among the respondents, only a few $31.71 \%$ reported ever using contraceptives. As high as $54.64 \%$ of pregnant teenagers and $88.06 \%$ of the non-pregnant teenagers reported never using any form of contraceptive. This corresponds with the GSS, (2010) [8] report which placed Ghana among the nations with the lowest usage of contraceptives in women between the ages of 15 and 19 years. The study also found that about $43.21 \%$ of the respondents who were sexually active did not use any form of contraceptive during their first sexual intercourse. This finding is not consistent with the Southwark teenage pregnancy report (2010) which indicated that most sexually active teenagers do not use any form of contraceptive during their first sexual experience. The findings, however, contradict a Guttmacher Institute report in 2014 that showed that $78 \%$ of females and $85 \%$ of male teenagers in the USA use contraceptives during their first sexual experience. However, this study found that there was a significant association between knowledge on contraceptives and contraceptive use and teenage pregnancy hence found to influence teenage pregnancy in the municipality.

\section{Conclusions}

In conclusion, our findings indicate that socio-demographic factors such as age, marital status, school enrollment status and the reported occupation of the participants had a significant statistical association with their pregnancy status. Other potential contributing factors included age at first sex, peer influences 
opinion on sex, electronic media influence, whether parents live together, use of internet for social activities, types of social activities, religious activities include sex education, source of information on SRH, Social media activity influence on sexual behavior, and knowledge of contraceptive and its usage.

Teenage pregnancies are still a major health concern in the municipality, Africa and elsewhere in the world. The increase in the number is causing great concern and is becoming a critical issue. Teenage mothers' socio-economic advancement, education and job opportunities are limited and stunted by premature pregnancy; therefore, there is a high demand for addressing these problems in order to curb the problem and also to put urgent attention to every section of society in order to prevent family life from disintegrating completely.

Since the study indicated that most of the teenagers who were pregnant were not in school, there is, therefore, the need to task Ghana Education Service to encourage education among teenagers, especially the female teenagers since a longer stay in school help to avoid early sexual debut and eventually pregnancy and also strengthen and intensify reproductive health education programs in school. Similar programs should also be targeted to the young girls and boys in the communities undergoing various apprenticeship training.

The Municipal Assembly under the auspices of the Municipal Health Directorate can deploy "Peer educators" to educate their fellow teenagers on sex education which covers reproductive health, use of contraceptives and consequences of risky sexual behaviors. Other relatives of the teenagers must also be educated and encouraged to educate them about the need to possibly abstain from sexual intercourse prior to adulthood and marriage.

The electronic and print Media should help produce features and editorials on the importance of ensuring all teenagers have access to advise on reproductive health and the means to prevent unwanted pregnancy. The teenagers can also be encouraged to use social media for the purpose of education.

Despite the contribution of this study to scientific knowledge, it cannot go without mentioning some inherent limitations that came with it. Thus, most of the information gathered was self-reported and any memory recall challenge could obviously introduce some form of biasness to the findings. For example, getting information on age at first sexual intercourse was very confidential and private among the respondents and very difficult for the research team to ascertain the validity of the answers provided. Also, the small nature of the sampled size used will make it impossible to generalize the key findings to a larger population. Further comprehensive qualitative research work could be done as a follow-up study.

\section{Conflicts of Interest}

All authors declare no conflict of interest.

\section{Authors' Contributions}

This work was carried out in collaboration between all authors. JYB and SM par- 
ticipated in conceiving the study and in the development of data collection tools. JYB carried out data collection. SM and JYB participated in the data analysis and drafting of the manuscript. All authors read and approved the final manuscript.

\section{References}

[1] Miller, B.C. (2002) Family Influences on Teenage Sexual and Contraceptive Behaviour. Journal of Sex Responsibility, 39, 22-26.

https://doi.org/10.1080/00224490209552115

[2] WHO (2011) Adolescent Pregnancy. https://www.who.int/en/news-room/factsheets/detail/adolescent-pregnancy

[3] Kost, K. and Henshaw, S. (2014) U.S. Teenage Pregnancies, Births and Abortions, 2010: National and State Trends by Age, Race, and Ethnicity. Allan Guttmacher Institute, New York, 1-29.

https://www.guttmacher.org/sites/default/files/report_pdf/ustptrends10.pdf

[4] UNICEF (2008) Child Protection: Teenage Pregnancies. https://www.unicef.org/publications/index_pubs_2008.html

[5] Tripp, J. and Viner, R. (2005) ABC of Adolescence: Sexual Health, Contraception, and Teenage Pregnancy. British Medical Journal, 330, 590-593. https://doi.org/10.1136/bmj.330.7491.590

[6] https://www.un.org/esa/socdev/documents/youth/fact-sheets/youth-definition.pdf

[7] WHO (2014) Adolescent Pregnancy. https://apps.who.int/iris/bitstream/handle/10665/112320/WHO_RHR_14.08_eng.pdf

[8] WHO (2008) Adolescent Pregnancy. https://apps.who.int/iris/bitstream/handle/10665/42903/9241591455_eng.pdf?seque $\underline{\text { nce }=1}$

[9] Ghana Statistical Services (2012) Population and Housing Census Post Enumeration Survey Report, 2010. Accra.

http://www.statsghana.gov.gh/gssmain/fileUpload/pressrelease/2010_PHC_Nationa 1_Analytical_Report.pdf

[10] Ghana Health Service (2009) Adolescent Pregnancy. Reproductive and Child Health Unit.

https://www.ghanahealthservice.org/downloads/2015_FAMILY_HEALTH_DIVISI ON_ANNUAL_REPORT.pdf

[11] Selby, H. (2012) Teenage Pregnancy: Who Is to Be Blamed-The Child, Parent or Society?

https://www.modernghana.com/lifestyle/1512/5/teenage-pregnancy-who-is-to-be-bl amedthe-child-pa.html

[12] Odu, K.B. and Ayodele, J.C. (2007) The Menace of Teenage Motherhood in Ekiti State, Middle-East. Journal of Scientific Research, 2, 157-161.

https://www.idosi.org/mejsr/mejsr2(3-4)/16.pdf

[13] Vibe Ghana (2014) Teenage Pregnancy High in Sunyani West District. http://vibeghana.com/2014/09/18/teenage-pregnancy-high-in-sunyani-west-district

[14] Lower Many Krobo Municipal Health Directorate (2017) Ghana Health Service, Annual Report. http://www.ghanahealthservice.org

[15] Tobias, F. (2001) Data Analysis Methods. Research Methods and Designs. https://dissertationeducators.co.uk/services/research-methodology.php

[16] Osuala, E.C. (2001) Introduction to Research Methodology. 3rd Edition, Africana- 
Fep Publishers Limited, Onitsha.

https://www.scribd.com/document/7089904/Lect-1-Meaning-and-Charateristics-ofReseearch

[17] Drummond, K. (1998) Research Methods for Therapists. Thorne Publishers, London. https://www.academia.edu/35741217/factors_contributing_to_teenage_pregnancies in_tunduru_district_council

[18] Ghana Statistical Service, Ghana Health Service (GHS) and ICF Macro (2014) Ghana Demographic and Health Survey. GSS, GHS and ICF Macro, Accra. https://dhsprogram.com/pubs/pdf/fr307/fr307.pdf

[19] Ghana Statistical Service (GSS), Ghana Health Service (GHS) and ICF Macro (2009) Ghana Demographic and Health Survey. GSS, GHS \& ICF Macro, Accra. https://www.who.int/fctc/reporting/party_reports/ghana_annex1_dhs_2008_final_r eport.pdf?ua $=1$

[20] Selkie, E.M., Benson, M. and Moreno, M. (2011) Adolescents' Views Regarding the Uses of Social Networking Websites and Test Massaging for Adolescent Sexual Health Education. American Journal of Health Education, 42, 205-212. https://doi.org/10.1080/19325037.2011.10599189

[21] Strasburger, V.C. (2005) Adolescents, Sex, and the Media: Oooo, Baby, Baby-A Q\&A. Adolescent Medicine Clinics, 16, 269-288.

https://doi.org/10.1016/j.admecli.2005.02.009

[22] Chandra, A., Martino, S.C. and Collins, R.L. (2008) Does Watching Sex on Television Predict Teen Pregnancy? Of Findings from a National Longitudinal Survey Youth. Pediatrics, 122, 1047-1054. https://doi.org/10.1542/peds.2007-3066

[23] Connel, R.S. (2009) Academic Libraries, Facebook and Myspace and Student Outreach: A Survey of Student Options. Portal: Libraries and the Academy, 9, 25-36. https://eric.ed.gov/?id=EJ825201 https://doi.org/10.1353/pla.0.0036

[24] Gyan, C. (2013) The Effects of Teenage Pregnancy on the Educational Attainment of Girls at Chorkor a Suburb of Accra. Journal of Educational and Social Research, 3, 53-60. https://www.mcser.org/journal/index.php/jesr/article/viewFile/542/567 https://doi.org/10.5901/jesr.2013.v4n3p53

[25] Amuyunzu-Nyamongo, M., Biddlecom, A.E., Ouedraogo, C. and Woog, V. (2005) Qualitative Evidence on Adolescents' Views of Sexual and Reproductive Health in Sub-Saharan Africa. Occasional Report No. 16, Alan Guttmacher Institute, New York, 1-46.

https://www.guttmacher.org/sites/default/files/pdfs/pubs/2005/03/01/or16.pdf

[26] Smetana, J.G., Campione-Barr, N. and Metzger, A. (2006) Adolescent Development in Interpersonal and Societal Contexts. Annual Review of Psychology, 57, 255-284. https://doi.org/10.1146/annurev.psych.57.102904.190124

[27] Adu-Gyamfi, E. (2014) Assessing the Effect of Teenage Pregnancy on Achieving Universal Basic Education in Ghana: A Case Study of Upper Denkyira West District. Journal of Education and Practice, 5, 46-60. https://www.iiste.org/Journals/index.php/JEP/article/viewFile/13910/14062

[28] Awusabo-Asare, K., Biddlecom, A., Kumi-Kyereme, A. and Patterson, K. (2006) Adolescent Sexual and Reproductive Health in Ghana: Results from the $2004 \mathrm{Na}$ tional Survey of Adolescents. Occasional Report No. 22, Allan Guttmacher Institute, New York, 1-148.

https://www.guttmacher.org/sites/default/files/pdfs/pubs/2006/06/08/or22.pdf 